\title{
Multiparameter analysis using cell cycle biomarkers for small-size lung adenocarcinoma: Prognostic implications
}

\author{
TOMOHIRO HARUKI $^{1,2}$, KOHEI SHOMORI ${ }^{1}$, TATSUSHI SHIOMI ${ }^{1}$, \\ YUJI TANIGUCHI $^{2}$, HIROSHIGE NAKAMURA ${ }^{2}$ and HISAO ITO ${ }^{1}$ \\ ${ }^{1}$ Division of Organ Pathology, Department of Microbiology and Pathology, Faculty of Medicine, \\ Tottori University, Yonago-city, Tottori 683-8503; ${ }^{2}$ Division of General Thoracic \\ Surgery, Tottori University Hospita, Yonago-city, Tottori 683-8504, Japan
}

Received January 23, 2012; Accepted April 6, 2012

DOI: $10.3892 /$ or.2012.1894

\begin{abstract}
Cell cycle-related molecules play crucial roles in maintaining genomic stability, and can also serve as biomarkers of cell cycle phase distribution at the same time. In this study, we used multiparameter analysis of various biomarkers to investigate their utility for the evaluation of tumor proliferation activities and the prognosis of patients with small-size lung adenocarcinoma. We performed immunohistochemical analysis using five cell cycle-related biomarkers (MCM7, Ki-67, Geminin, Aurora A and H3S10ph) for 102 surgically resected small-size lung adenocarcinomas. We classified them into three phenotypes based on the dominant cell cycle phase distribution of the tumor cell population, and evaluated whether these phenotypes were associated with clinicopathological factors and survival. Phenotype I (MCM7-negative tumors; $\mathrm{n}=56$ ) was correlated with high or moderate differentiation and reduced local invasiveness (pleural and lymphovascular invasion) compared with phenotype II (MCM7-, Ki-67- and Geminin-positive tumors; $\mathrm{n}=23$ ) and phenotype III (MCM7-, Aurora A- and H3S10ph-positive tumors; $n=17$ ). Five-year survival rates of phenotypes I, II and III were 89.8, 55.4 and $38.6 \%$, respectively, with a significant difference between them $(\mathrm{P}<0.01)$. Multivariate analysis revealed that phenotypes II and III were independent prognostic factors in the 79 patients with stage I lung adenocarcinoma. Multiparameter analysis using cell cycle biomarkers for small-size lung adenocarcinoma provided novel insights into the cell cycle phase distribution of dynamic tumor cell populations in vivo; it may be possible to evaluate tumor proliferation activities and patient prognosis more precisely if this analytical procedure is used.
\end{abstract}

Correspondence to: Dr Tomohiro Haruki, Division of Organ Pathology, Department of Microbiology and Pathology, Faculty of Medicine, Tottori University, 86 Nishi-cho, Yonago-city, Tottori 683-8503, Japan

E-mail: tomohiro19780703@yahoo.co.jp

Key words: small lung adenocarcinoma, multiparameter analysis, cell cycle-related biomarkers, phenotype, immunohistochemical analysis, prognosis

\section{Introduction}

Lung cancer is currently the leading cause of cancer death in Japan and other industrialized countries (1). Although surgery is the most effective and definitive therapeutic modality, especially for patients with early-stage non-small cell lung cancer (NSCLC), their postoperative survival rate remains poor. To improve the postoperative prognosis, definite predictive biomarkers should be used to detect the poor prognosis cohort and intensive postoperative therapy should then be performed on them.

$\mathrm{Ki}-67$, which is known as a representative cell proliferative marker, has been used widely for various malignancies including lung cancer to evaluate the malignant potential or the proliferative activity of the tumor (2-6). In addition, we have focused on the cell cycle-related proteins as tumor proliferative biomarkers and revealed that some of these proteins are useful for the prognostic prediction of patients with lung adenocarcinoma $(7,8)$. There have also been various other studies on the prognostic markers of NSCLC. However, these have not actually contributed to improving the prognosis of patients with early-stage NSCLC. Although almost all of these previous studies described the prognostic significance of a single biomarker, recent investigations have suggested that prognostic prediction is more reliable when multiparameter analysis with several biomarkers is performed than with analysis with a single one (9-11).

There are significant interactions between numerous molecules around the $\mathrm{S}$ phase as the DNA replication period and the $\mathrm{M}$ phase as the cell mitotic period. Among these molecules, the minichromosome maintenance families (MCM2-7) and Geminin play crucial roles in the DNA replication licensing pathway, which restricts the replication of the chromosome to only once per cell cycle (12). Briefly, MCM proteins (MCM2-7) assemble on the origin of replication with other initiator proteins and facilitate DNA unwinding by acting as a DNA helicase. After DNA replication is initiated during the cell cycle, Geminin inhibits re-uploading of the MCM proteins onto chromatin, thus preventing DNA re-replication in the same cell cycle (13). It has been confirmed that these proteins are useful biomakers that reflect the proliferative activity of the tumor cells and predict the survival of patients 


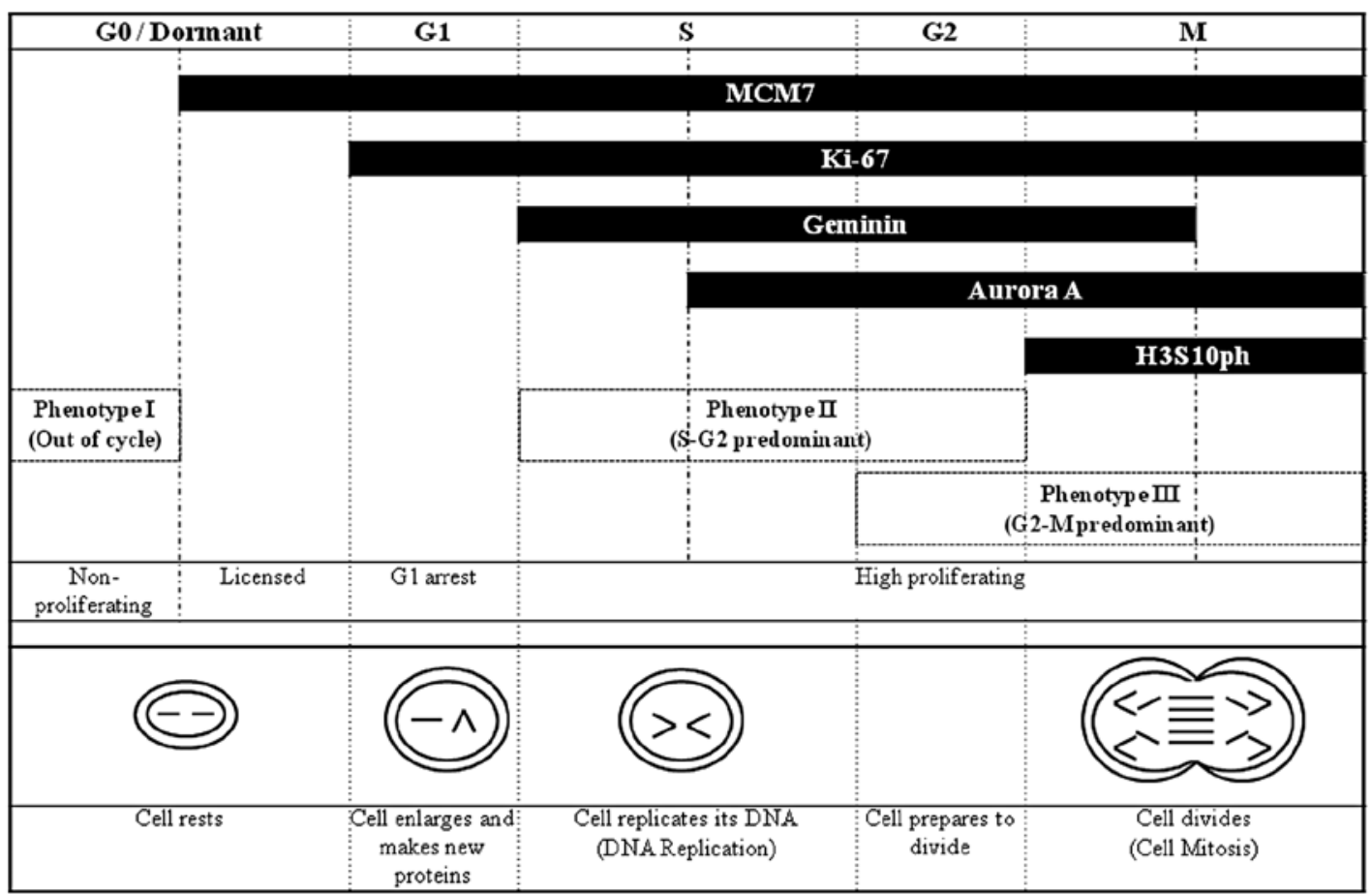

Figure 1. Phase-specific distribution of cell cycle biomarkers. MCM7 is expressed throughout the cell cycle (G1-S-G2-M phases) but is tightly downregulated during G0 phase. Ki-67 is expressed during all phases of the cell cycle except for G0, and Geminin is expressed during S-G2-M phases but not in G0 and G1 phases. Aurora A is expressed during S-G2-M phases, and phosphohistone (H3S10ph) is expressed only in M phase.

with various types of cancer (5-11,14-18). Aurora A, known as a member of the serine/threonine kinase family, controls a subset of critical mitotic events including centrosome maturation and separation, as well as chromosome orientation and segregation (19). In addition, histone $\mathrm{H} 3$ is as substrate for the Aurora kinases and is phosphorylated on serine 10 only in mitosis, producing a phosphohistone (H3S10ph) (20). Gene amplification and protein overexpression of Aurora kinases may lead to centrosome function disorder, chromosomal instability, and carcinogenesis (21). Moreover, there are some reports concerning significant correlations between Aurora A and the tumor malignant grade or the prognosis of patients with various types of cancer including NSCLC $(9,10,22-28)$.

These cell cycle-related proteins (MCM7, Ki-67, Geminin, Aurora A and H3S10ph) can also serve as markers for the cell cycle phase distribution on immunohistochemistry, as shown in Fig. 1. Therefore, immunohistochemical multiparameter analysis using these biomarkers allows a detailed evaluation of the kinetics of complex dynamic tumor cell populations (29). In the present study, we classified small $(3 \mathrm{~cm}$ or less in diameter) invasive lung adenocarcinomas [pure bronchioloalveolar carcinomas (BACs) were not included] into three phenotypes based on the dominant cell cycle phase of the tumor cell population. In addition, we evaluated whether these phenotypes were associated with clinicopathological factors and patient survival.

\section{Materials and methods}

Patients and surgical specimens. This study enrolled a total of 102 patients with lung adenocarcinoma who underwent curative resection at Tottori University Hospital between January 1997 and December 2006. All the 102 tumors were diagnosed as invasive lung adenocarcinoma (pure BACs were not included) with a maximum diameter of $\leq 3 \mathrm{~cm}$ (pT1). Routinely, neutral buffered formalin ( $\mathrm{pH}$ 7.4)-fixed and paraffin-embedded tumor tissue samples were sectioned in $3 \mu \mathrm{m}$ serial slices. The sections were stained using hematoxylin and eosin (HE) and Elastic van Gieson (EvG) stain.

The patients included 53 males and 49 females, with a mean age of $67.8 \pm 11.2$ (SD) years (range, 26-85 years). Histological specimens were reviewed by the first author and qualified pathologists (K.S. and H.I.) and assessed for histological subtype and tumor grade according to the World Health Organization (WHO) criteria (1). These 102 tumors consisted of 7 acinar, 20 papillary, 11 solid with mucin and 64 adenocarcinoma with mixed subtypes. Well-, moderately, and poorly differentiated adenocarcinomas were present in 28 , 59, and 15 cases, respectively. Tumor stage of the disease at pathological diagnosis was determined according to the UICC guidelines (6th edition) of the TNM classification of malignant tumor (30). The pathological stage of lung cancer was I in 83 patients, II in 5 and III in 14. Pleural invasion was classified as pl0, pl1, pl2 and pl3; pl0 included tumor with no pleural involvement or reaching the visceral pleura but not extending beyond its elastic pleural layer; pl1 included tumor reaching visceral pleural elastic layer but not exposed on the pleural surface; p12 included tumor exposed on the pleural surface; and pl3 included tumor invading parietal pleura or chest wall. We defined pl0 as pleural invasion-negative and pl1-3 as -positive. As for lymphatic and vascular invasion, we determined the status of invasion-positive or -negative on the basis of whether 

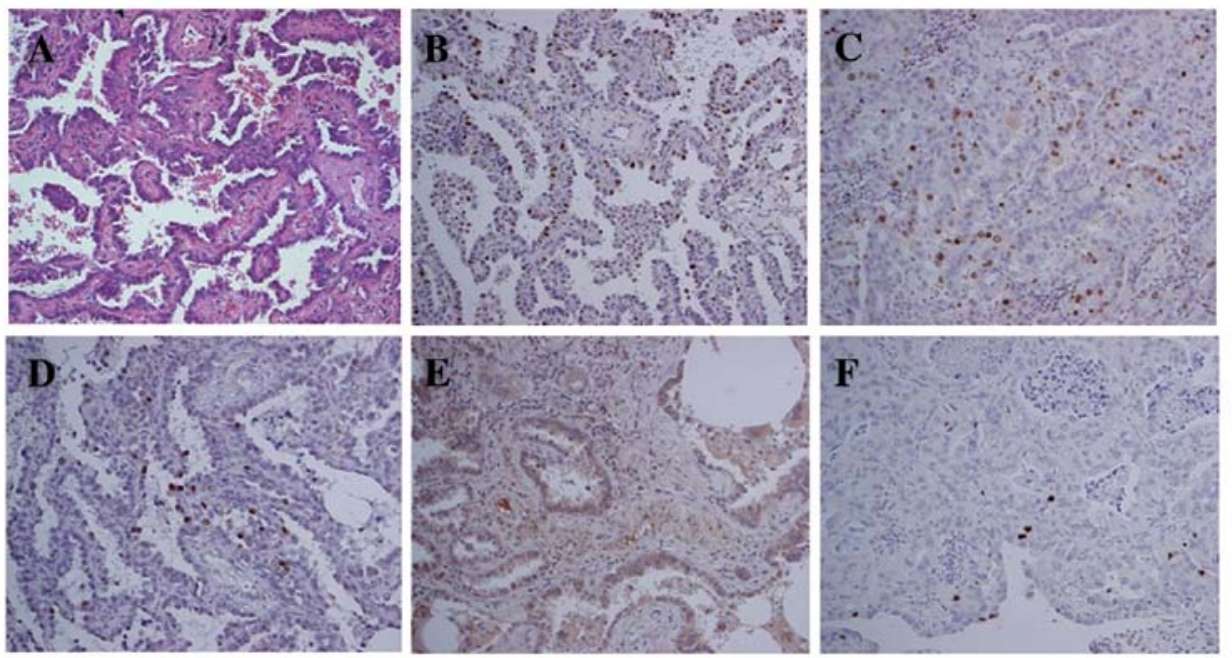

Figure 2. Representative cases of lung adenocarcinoma (papillary subtype) (A) and immunohistochemical staining positive for MCM7 (B), Ki-67 (C), Geminin (D), Aurora A (E) and H3S10ph (F). Immunoreactivity of MCM7, Ki-67, Geminin, and H3S10ph is mainly observed in the nuclei of tumor cells, whereas that of Aurora A is noted in the cytoplasm of tumor cells

or not tumor cells were identifiable in the lymphatic lumen or blood vessel lumen, respectively (31). The slides of EvG stain were used supplementarily for evaluation of lymphatic and vascular invasion. Among all the 102 subjects, pleural invasion was negative in 70 patients and positive in 32 , lymphatic invasion was negative in 37 and positive in 65, and vascular invasion was negative in 62 and positive in 40 . The median follow-up period was 56.4 months (range, 2-146 months). The study protocol was approved by the institutional review board, and informed consent was obtained from all patients for tumor sample collection.

Immunohistochemistry. Tissue sections were de-waxed in xylene, rehydrated through a graded series of ethanol solution, rinsed in distilled water for $5 \mathrm{~min}$, and then immersed in $0.3 \%$ hydrogen peroxide $\left(\mathrm{H}_{2} \mathrm{O}_{2}\right)$ in methanol for $30 \mathrm{~min}$ to block endogenous peroxidase. For antigen retrieval, sections were microwaved in $0.01 \mathrm{~mol} / \mathrm{l}$ sodium citrate-buffered saline (pH 6.0) for $20 \mathrm{~min}$ at $95^{\circ} \mathrm{C}$ using a microwave processor model MI-77 (Azumaya, Tokyo, Japan). After being rinsed in PBS for $5 \mathrm{~min}$, the slides were pre-blocked with a solution of $2 \%$ FBS at room temperature for $20 \mathrm{~min}$ and incubated at $4^{\circ} \mathrm{C}$ overnight with the antibodies. A subsequent reaction was initiated by the streptavidin-biotin-peroxidase complex technique (SAB method) using a Histofine SAB-PO (M) immunohistochemical staining kit (Nichirei, Tokyo, Japan). The immunoreactions

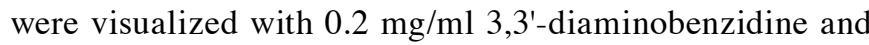
$20 \mu \mathrm{l} / \mathrm{dl}$ hydrogen peroxide in $0.05 \mathrm{M}$ Tris-HCl buffer ( $\mathrm{pH} 7.6$ ). Finally, the slides were counterstained with $0.1 \%$ hematoxylin and then dehydrated and mounted.

Antibodies. We used the following primary antibodies for immunohistochemistry: mouse anti-MCM7 antibody (1:100 dilution; Santa Cruz Biotechnology, Santa Cruz, CA, USA), mouse anti-Ki-67 antibody (1:50 dilution; Dako, Glostrup, Denmark), rabbit anti-Geminin antibody (1:100 dilution; Santa Cruz Biotechnology), mouse anti-Aurora A antibody (1:100 dilution; Novocastra, Newcastle, UK), and rabbit polyclonal antibody to Histone H3 (phospho S10) (1:100 dilution; Abcam, Cambridge, UK).

Evaluation of immunohistochemical findings. To evaluate MCM7, Ki-67, Geminin, and H3S10ph expression, positively stained tumor cell nuclei were counted. Counts were performed in high-magnification fields using the FLOVEL Image Filling System FlvFs (FLOVEL Inc., Tachikawa, Japan). Both positive and negative cells within the fields were counted and any stromal or inflammatory cells were excluded. For MCM7, $\mathrm{Ki}-67$, Geminin, and H3S10ph, at least 500 tumor cells were counted in areas showing a high frequency of cells with nuclei positive for such expression, and these labeling indices (LIs) were calculated using the following formula: $\mathrm{LI}=$ number of positive cells/total number of cells x 100. On the other hand, the immunohistochemical staining of Aurora A was scored into the following four grades on the basis of the expression levels in the tumor cell cytoplasm: $3+$ (strongly positive), 2+ (intermediately positive), 1+ (weakly positive), and 0 (negative). The pathological evaluation was performed by three authors (T.H., K.S. and H.I.) independently. In reference to the average value of each LI, we decided that the cut-off values of MCM7, Ki-67, Geminin, and H3S10ph were 15, 10, 5, and 3\%, respectively. As for Aurora A, tumors with scores of 2+ and $3+$ were considered to be positive. We chose and determined these cut-off values and scores through trial and error. To confirm the specificity of the immunostaining results, sections immunoreacted without the primary antibodies were used as negative controls.

Statistical analysis. Data were analyzed using StatView version 5.0 (SAS Inc., Cary, NC, USA). Kruskal-Wallis test and $\chi^{2}$ test were used in evaluation of the relationship between cell-cycle phenotypes and clinicopathological parameters. The survival rates were estimated with the Kaplan-Meier method and statistical analyses were carried out using the log-rank test. A P-value $<0.05$ was considered to be significant in statistical analyses. Univariate and multivariate Cox regression analyses 


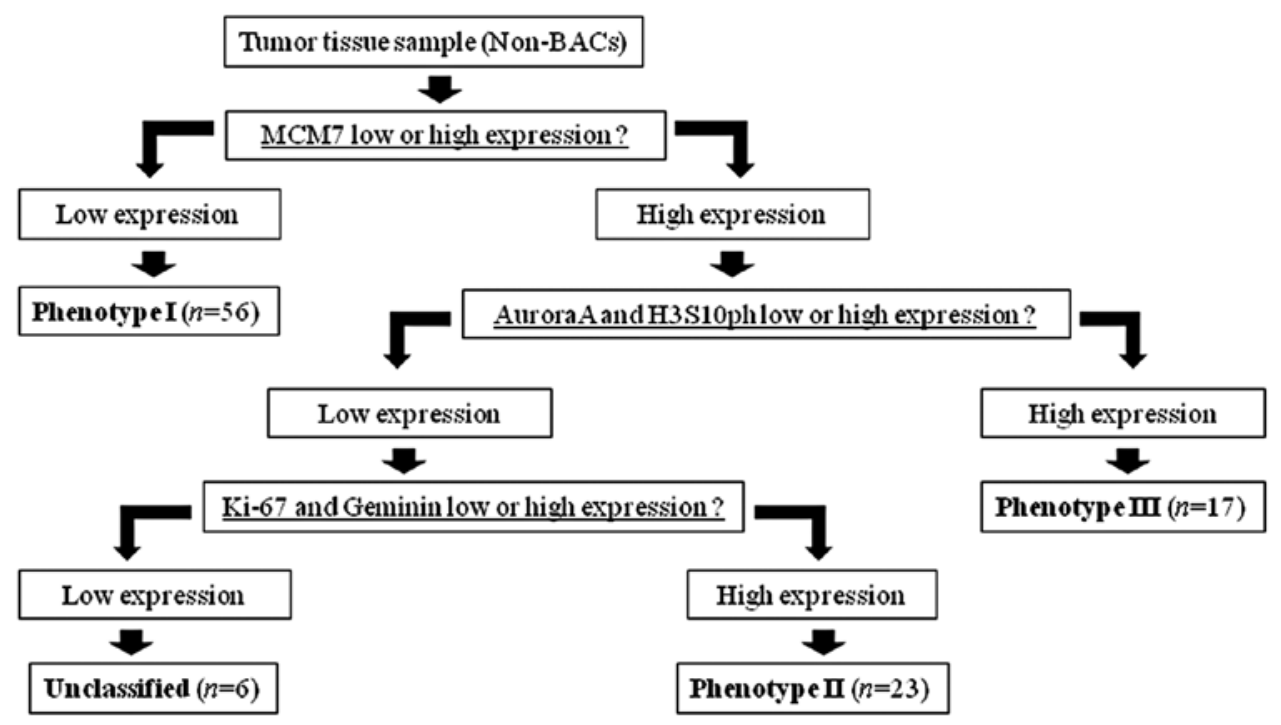

Figure 3. The 102 non-BAC tumors were classified into three phenotypes according to this cell-cycle phase algorithm. Phenotype I was MCM7-negative, phenotype II was MCM7-, Ki67-, and Geminin-positive (S-G2 phase dominant), and phenotype III was MCM7-, Aurora A-, and H3S10ph-positive (G2-M phase dominant).
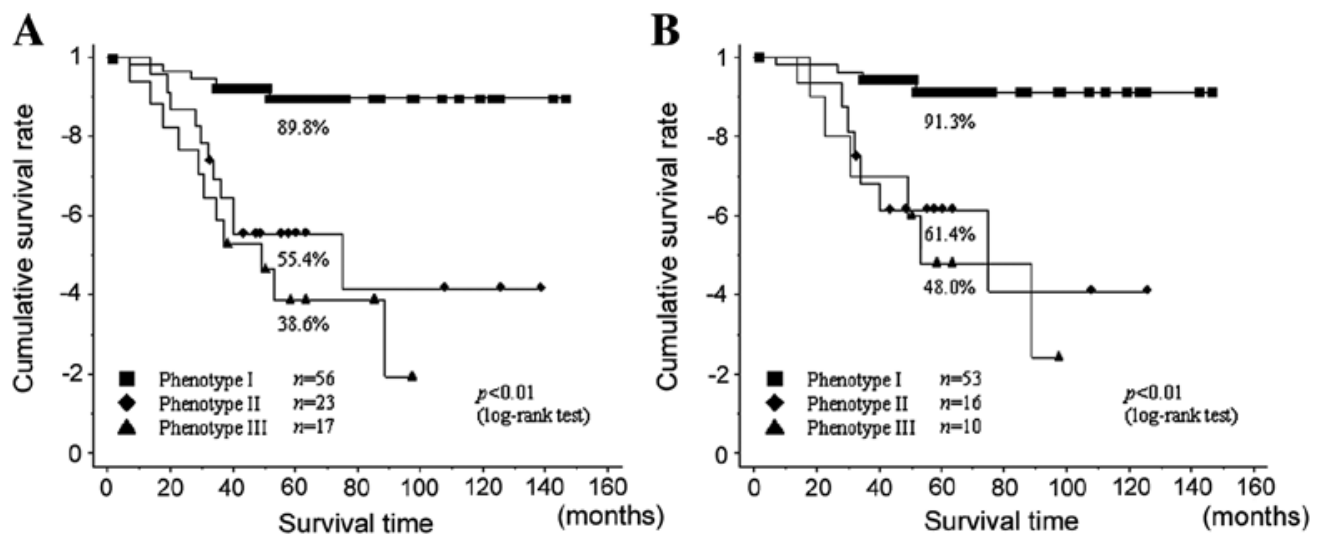

Figure 4. (A) The 5-year survival rates of all patients with phenotypes I, II, and III were 89.8, 55.4 and $38.6 \%$, respectively, with a statistically significant difference $(\mathrm{P}<0.01$; log-rank test). (B) Of patients in stage I, the 5-year survival rates for phenotypes I, II and III were 91.3, 61.4 and $48.0 \%$, respectively, which were also significantly different $(\mathrm{P}<0.01 ; \log$-rank test).

were used to evaluate the contribution of various factors to the overall survival of all patients.

\section{Results}

Expression of cell cycle biomarkers in lung adenocarcinoma. Fig. 2 shows representative cases of immunohistochemical staining positive for MCM7, Ki-67, Geminin, Aurora A, and H3S10ph (Fig. 2). Immunoreactivity of MCM7, Ki-67, Geminin and H3S10ph was mainly observed in the nuclei of tumor cells, whereas that of Aurora A was noted in the cytoplasm of tumor cells.

Cell cycle phase algorithm in lung adenocarcinoma. The cell cycle biomarker proteins, MCM7, Ki-67, Geminin, Aurora A, and H3S10ph, provide information on their specific cell cycle phase distribution: MCM7 protein is expressed throughout the cell cycle (G1-S-G2-M phases) but is tightly downregulated during exit into the out-of-cycle quiescent phase (G0 phase), corresponding to a differentiated or senescent state (11). Ki-67 is expressed during all phases of the cell cycle except for G0, while Geminin is expressed during the S-G2-M phases but not in G0 and G1 phases (17). Aurora A accumulates during $\mathrm{S}$ phase and reaches a peak in G2-M phase, followed by rapid degradation at the end of mitosis, and phosphohistone (H3S10ph) represents a biomarker of the only M-phase transition (10) (Fig. 1).

In this study, we defined the cell cycle phase algorithm with cell cycle biomarkers for lung adenocarcinomas by reference to the above cell cycle distribution (Fig. 3). On the basis of this algorithm, we classified the subjects (102 tumors) into the following phenotypes: i) phenotype I $(n=56)$, MCM7-negative (out-of-cycle) tumors; ii) phenotype II ( $\mathrm{n}=23)$, MCM7-, Ki67-, and Geminin-positive (S-G2 phase dominant) tumors; iii) phenotype III ( $\mathrm{n}=17)$, MCM7-, Aurora A-, and H3S10phpositive (G2-M phase dominant) tumors; iv) unclassified (n=6), MCM-positive, but Ki-67-, Geminin-, Aurora A-, and H3S10ph-negative tumors. 
Table I. Relationship between cell-cycle phenotype and clinicopathological parameters.

\begin{tabular}{|c|c|c|c|c|}
\hline & $\begin{array}{c}\text { Phenotype } \mathrm{I}^{\mathrm{a}} \\
\mathrm{n}=56(\%)\end{array}$ & $\begin{array}{c}\text { Phenotype } \mathrm{II}^{\mathrm{b}} \\
\mathrm{n}=23(\%)\end{array}$ & $\begin{array}{c}\text { Phenotype } \mathrm{III}^{\mathrm{c}} \\
\mathrm{n}=17(\%)\end{array}$ & P-value \\
\hline \multicolumn{5}{|l|}{ Age (years) } \\
\hline Mean \pm SD & $66.6 \pm 12.0$ & $71.0 \pm 8.8$ & $67.4 \pm 11.9$ & $0.19^{\mathrm{d}}$ \\
\hline \multicolumn{5}{|l|}{ Gender } \\
\hline Male & $26(46)$ & $14(61)$ & $10(59)$ & $0.42^{\mathrm{e}}$ \\
\hline Female & $30(54)$ & $9(39)$ & $7(41)$ & \\
\hline \multicolumn{5}{|c|}{ Histological grade } \\
\hline Well & $24(43)$ & $4(17)$ & $0(0)$ & $<0.01^{\mathrm{e}}$ \\
\hline Moderately & $30(53)$ & $10(44)$ & $13(76)$ & \\
\hline Poorly & $2(4)$ & $9(39)$ & $4(24)$ & \\
\hline \multicolumn{5}{|c|}{ Tumor size (mm) } \\
\hline Mean \pm SD & $18.7 \pm 5.7$ & $22.2 \pm 4.6$ & $22.1 \pm 4.1$ & $0.01^{\mathrm{d}}$ \\
\hline \multicolumn{5}{|c|}{ Pleural invasion } \\
\hline Negative & $43(77)$ & $16(70)$ & $10(59)$ & $0.08^{\mathrm{e}}$ \\
\hline Positive & $13(23)$ & $7(30)$ & $7(41)$ & \\
\hline \multicolumn{5}{|c|}{ Lymphatic invasion } \\
\hline Negative & $28(50)$ & $4(17)$ & $3(18)$ & $<0.01^{\mathrm{e}}$ \\
\hline Positive & $28(50)$ & $19(83)$ & $14(82)$ & \\
\hline \multicolumn{5}{|c|}{ Vascular invasion } \\
\hline Negative & $44(79)$ & $11(48)$ & $4(24)$ & $<0.01^{\mathrm{e}}$ \\
\hline Positive & $12(21)$ & $12(52)$ & $13(76)$ & \\
\hline \multicolumn{5}{|c|}{ Lymph node metastasis } \\
\hline No & $53(95)$ & $16(69)$ & $10(59)$ & $<0.01^{\mathrm{e}}$ \\
\hline N1 & $0(0)$ & $2(9)$ & $2(12)$ & \\
\hline $\mathrm{N} 2$ & $3(5)$ & $5(22)$ & $5(29)$ & \\
\hline \multicolumn{5}{|c|}{ Pathological stage } \\
\hline I & $53(95)$ & $16(69)$ & $10(59)$ & $<0.01^{\mathrm{e}}$ \\
\hline II & $0(0)$ & $2(9)$ & $2(12)$ & \\
\hline III & $3(5)$ & $5(22)$ & $5(29)$ & \\
\hline
\end{tabular}

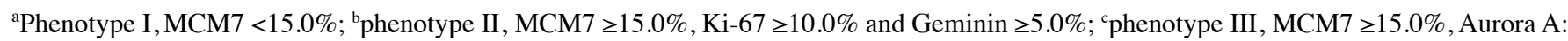
+2 or +3 and $\mathrm{H} 3 \mathrm{~S} 10 \mathrm{ph} \geq 3.0 \%$; ${ }^{\mathrm{K}}$ Kruskal-Wallis test; ${ }^{\mathrm{e}} \mathrm{Chi}$-square test.

Relationship between cell cycle phenotypes and clinicopathological parameters. We evaluated the correlations between some clinicopathological parameters and the above phenotypes. The phenotypes were significantly correlated with histological grade $(\mathrm{P}<0.01)$, tumor size $(\mathrm{P}=0.01)$, lymph node metastasis $(\mathrm{P}<0.01)$, and pathological stage $(\mathrm{P}<0.01)$, but not with age $(\mathrm{P}=0.19)$, gender $(\mathrm{P}=0.42)$, and pleural invasion $(\mathrm{P}=0.08)$ (Table I).

Analysis of prognostic significance. Next, the cumulative overall survivals of those with the three phenotypes were analyzed using the Kaplan-Meier method and log-rank test. For all patients, the 5-year survival rates of those with phenotypes I, II, and III tumors were $89.8,55.4$, and $38.6 \%$, respectively, with a statistically significant difference $(\mathrm{P}<0.01$; log-rank test $)$ (Fig. 4A). Of patients in stage I, the 5-year survival rates were 91.3, 61.4 and $48.0 \%$, respectively, with a significant differ- ence between them $(\mathrm{P}<0.01$; log-rank test) (Fig. 4B). Next, we performed analyses to evaluate the contribution of potential prognostic markers to the overall survival in the 79 stage I patients. A multivariate analysis of prognostic factors using a Cox proportional hazard model confirmed that phenotype II $[\mathrm{P}=0.02$, Hazard ratio (HR), 5.01; 95\% CI, 1.34-18.7] and phenotype III $(\mathrm{P}=0.01, \mathrm{HR}, 5.50 ; 95 \% \mathrm{CI}, 1.39-21.8)$ were significant factors to predict poor survival in all subjects in this study (Table II).

\section{Discussion}

In this study, we have demonstrated that phenotype classification by immmunohistochemical multiparameter analysis using cell cycle-related biomarkers is a useful procedure to predict the degree of tumor malignant behavior and the prognosis of patients with small-size lung adenocarcinoma. 
Table II. Univariate and multivariate analysis for prognostic factors (79 patients with stage I).

\begin{tabular}{|c|c|c|c|c|}
\hline \multirow[b]{2}{*}{ Parameters } & \multirow{2}{*}{$\frac{\text { Univariate analysis }}{\text { P-value }}$} & \multicolumn{3}{|c|}{ Multivariate analysis } \\
\hline & & P-value & Hazard ratio & $95 \% \mathrm{CI}$ \\
\hline \multicolumn{5}{|l|}{ Age } \\
\hline $\begin{array}{l}\text { Young }(\leq 68) \\
\text { Old }(>68)\end{array}$ & 0.05 & & & \\
\hline \multicolumn{5}{|l|}{ Gender } \\
\hline $\begin{array}{l}\text { Female } \\
\text { Male }\end{array}$ & 0.04 & 0.35 & $\begin{array}{l}\text { Ref } \\
1.77\end{array}$ & $0.53-5.88$ \\
\hline \multicolumn{5}{|c|}{ Histological grade } \\
\hline $\begin{array}{l}\text { Well } \\
\text { Moderate }\end{array}$ & 0.04 & 0.73 & $\begin{array}{l}\text { Ref } \\
1.37\end{array}$ & $0.23-8.09$ \\
\hline Poorly & 0.01 & 0.83 & 1.26 & $0.16-10.1$ \\
\hline $\begin{array}{c}\text { Tumor size }(\mathrm{m} \\
\text { Small }(\leq 20) \\
\text { Large }(>20, \leq\end{array}$ & 0.3 & & & \\
\hline $\begin{array}{l}\text { Pleural invasio } \\
\text { Negative } \\
\text { Positive }\end{array}$ & 0.07 & & & \\
\hline \multicolumn{5}{|c|}{ Lymphatic invasion } \\
\hline $\begin{array}{l}\text { Negative } \\
\text { Positive }\end{array}$ & 0.01 & 0.17 & $\begin{array}{l}\text { Ref } \\
2.63\end{array}$ & $0.66-10.5$ \\
\hline \multicolumn{5}{|c|}{ Vascular invasion } \\
\hline $\begin{array}{l}\text { Negative } \\
\text { Positive }\end{array}$ & 0.02 & 0.65 & $\begin{array}{l}\text { Ref } \\
1.29\end{array}$ & $0.42-3.94$ \\
\hline \multicolumn{5}{|l|}{ Phenotype } \\
\hline I & & & Ref & \\
\hline II & $<0.01$ & 0.02 & 5.01 & $1.34-18.7$ \\
\hline III & $<0.01$ & 0.01 & 5.5 & $1.39-21.8$ \\
\hline
\end{tabular}

Our data suggest that there was a highly significant association between the phenotypes and histological grade, tumor local invasiveness including lymphatic and vascular invasion, and lymph node metastasis. Phenotype I, which consists of MCM7-negative tumors, was frequently noted in the well- or moderately-differentiated tumors and less frequently in the locally invasive tumors compared with phenotypes II and III. MCM7, one of the replication licensing factors, is expressed throughout all cell cycle phases (G1-S-G2-M), but is downregulated during exit into out-of-cycle states $(29,32)$. The repression of licensing contributes to replication arrest and loss of proliferative capacity, as cells exit the mitotic cycle into the out-of-cycle state. This allows a functional distinction between the proliferative state and the non-proliferative out-of-cycle state (33). Recent investigations suggest that the detection of MCM proteins is a powerful tool for assessing the proliferative potential of the cell. These unique biomarkers can clearly distinguish between active cycling cells and those in the out-of-cycle state in malignant disorders $(29,34,35)$. It is thought that phenotype I tumors may consist of a tumor cell population that is almost out of cycle, which might provide the lower tumor invasiveness and the good histological differentiation. From the perspective of cell cycle kinetics, we suggest that MCM7 is the most useful biomarker to distinguish the cell-cycle phenotypes firstly by means of immunohistochemical analysis.

Both phenotype II and III tumors might be characterized as having higher proliferative activity defined as MCM7, $\mathrm{Ki}-67$, and Geminin positivity (S-G2 phase dominant phenotype) and MCM7, Aurora A and H3S10ph positivity (G2-M phase dominant phenotype), respectively. These phenotypes were relatively well associated with the histologically poor degree of tumor differentiation and tumor local invasiveness. Geminin, which is also one of the DNA replication licensing factors, is expressed during the $\mathrm{S}, \mathrm{G} 2$, and $\mathrm{M}$ phases but not in G0 and G1 phases, and is degraded at $M$ phase without playing a specific role in cell division control (36). It has been suggested that Geminin might provide useful information about tumor proliferation activities that is equal or superior to that of MCM proteins or Ki-67. Moreover, there have been many studies demonstrating that immunohistochemical analysis with the combination of MCM proteins, 
Ki-67, and Geminin may be useful for predicting tumor proliferating activities or patient prognosis in various malignancies $(5,11,14,15,17,37)$. These findings are consistent with the present study, in which tumors that are positive for all of MCM7, Ki-67, and Geminin possess high proliferation potential, resulting in a high ratio of poorly differentiated and locally invasive tumors in phenotype II.

Aurora A, a family member of Aurora kinases, regulated G2-M transition by phosphorylation of histone H3, a key molecule in the conversion of the relaxed interphase chromatin to mitotic condensed chromosomes $(20,38)$. In the cell cycle, Aurora A is expressed during S-G2-M phases and its level is reduced rapidly after mitosis. It has been suggested that this mitotic kinase is associated with the development of malignant tumors and malignant alteration, and there have been some studies that showed a significantly positive correlation between Aurora A overexpression and aggressive tumor behavior, such as poor differentiation and nodal metastasis $(39,40)$. The present study was supportive of the biological mechanism by which Aurora A dysregulation at an early point during tumorigenesis might contribute to genetic instability, resulting in aggressive and local invasiveness in phenotype III tumors (9).

For survival analysis, the 5-year overall survival rates significantly differed among the phenotypes: the prognoses of the patients with phenotypes II and III were more unfavorable than those with phenotype I. Furthermore, multivariate analysis revealed that phenotypes II and III were independent prognostic factors in the 79 patients with stage I lung adenocarcinoma. Considering these results, it appears that this multiparameter analysis using cell cycle biomarkers provides more reliable and definite information about the prognostic implication of small-size lung adenocarcinoma when compared with the prognostic analysis with a single biomarker.

Cell cycle profiling by multiparameter analysis may have more useful features for determining cancer therapeutic significance. Loddo and colleagues (10) suggested that the cell cycle profiling of tumors has potential as a predictor of treatment response to cell cycle phase-specific chemotherapeutic agents, including small molecule inhibitors targeting the cell cycle machinery. For example, tegafur/ uracil (UFT) and taxanes are representative and commonly used anticancer drugs, especially in Japan, among various chemotherapeutic agents for NSCLC. The therapeutic target of UFT is thymidylate synthase (TS), especially in tumor cells in $\mathrm{S}$ phase, and its mechanism of action is ribonucleotide depletion, which leads to the arrest of tumor cells at the G1-S phase of the cell cycle. On the other hand, the target of taxanes is tubulin of tumor cells, especially those in M phase, and their antitumor effects result mainly from interference with the normal function of microtubules and the blockage of cell cycle progression in later G2-M phases via prevention of mitotic spindle formation (41). Other almost chemotherapeutic agents also have their specific acting phase in the cell cycle. These agents might work more effectively for tumor cells in a stage of cell cycle phase distribution where the target molecules exist. It might be possible to select these chemotherapeutic agents more effectively by multiparameter analysis to demonstrate the predominant cell cycle phase distribution of tumor cells.

\section{Acknowledgements}

We thank Mr. Itaki, Ms. Yamasaki, Ms. Iwatani and Ms. Tokuoka for excellent technical assistance.

\section{References}

1. Travis WD, Brambilla E, Muller-Hermelink HK and Harris CC (eds): World Health Organization Classification of Tumors. Pathology and Genetics of Tumors of the Lung, Pleura, Thymus and Heart. IARC Press, Lyon, p12-44, 2004.

2. Louis DN, Edgerton S, Thor AD and Hedley-Whyte ET: Proliferating cell nuclear antigen and Ki-67 immunohistochemistry in brain tumors: a comparative study. Acta Neuropathol 81: 675-679, 1991

3. Mehdi SA, Etzell JE, Newman NB, Weidner N, Kohman LJ and Graziano SL: Prognostic significance of Ki-67 immunostaining and symptoms in resected stage I and II non-small cell lung cancer. Lung Cancer 20: 99-108, 1998.

4. Haga Y, Hiroshima K, Iyoda A, et al: Ki-67 expression and prognosis for smokers with resected stage I non-small cell lung cancer. Ann Thorac Surg 75: 1727-1732, 2003.

5. Dudderidge TJ, Stoeber K, Loddo M, Atkinson G, Fanshawe T, Griffiths DF and Williams GH: Mcm2, Geminin, and Ki67 define proliferative state and are prognostic markers in renal cell carcinoma. Clin Cancer Res 11: 2510-2517, 2005.

6. Vargas PA, Cheng Y, Barrett AW, Craig GT and Speight PM: Expression of Mcm-2, Ki-67 and geminin in benign and malignant salivary gland tumours. J Oral Pathol Med 37: 309-318, 2008.

7. Fujioka S, Shomori K, Nishihara K, et al: Expression of minichromosome maintenance 7 (MCM7) in small lung adenocarcinomas (pT1): prognostic implication. Lung Cancer 65: 223-229, 2009.

8. Hashimoto K, Araki K, Osaki M, Nakamura H, Tomita K, Shimizu E and Ito H: MCM2 and Ki-67 expression in human lung adenocarcinoma: prognostic implications. Pathobiology 71: 193-200, 2004

9. Kulkarni AA, Loddo M, Leo E, et al: DNA replication licensing factors and aurora kinases are linked to aneuploidy and clinical outcome in epithelial ovarian carcinoma. Clin Cancer Res 13: 6153-6161, 2007.

10. Loddo M, Kingsbury SR, Rashid M, et al: Cell-cycle-phase progression analysis identifies unique phenotypes of major prognostic and predictive significance in breast cancer. Br J Cancer 100: 959-970, 2009.

11. Kayes OJ, Loddo M, Patel N, et al: DNA replication licensing factors and aneuploidy are linked to tumor cell cycle state and clinical outcome in penile carcinoma. Clin Cancer Res 15: 7335-7344, 2009

12. Nishitani $\mathrm{H}$ and Lygerou Z: Control of DNA replication licensing in a cell cycle. Genes Cells 7: 523-534, 2002.

13. Pitulescu M, Kessel M and Luo L: The regulation of embryonic patterning and DNA replication by geminin. Cell Mol Life Sci 62: $1425-1433,2005$

14. Tamura T, Shomori K, Haruki T, et al: Minichromosome maintenance-7 and geminin are reliable prognostic markers in patients with oral squamous cell carcinoma: immunohistochemical study. J Oral Pathol Med 39: 328-334, 2010.

15. Torres-Rendon A, Roy S, Craig GT and Speight PM: Expression of $\mathrm{Mcm} 2$, geminin and Ki67 in normal oral mucosa, oral epithelial dysplasias and their corresponding squamous-cell carcinomas. Br J Cancer 100: 1128-1134, 2009.

16. Nishihara K, Shomort K, Fujioka S, et al: Minichromosome maintenance protein 7 in colorectal cancer: implication of prognostic significance. Int J Oncol 33: 245-251, 2008.

17. Nishihara K, Shomori K, Tamura T, Fujioka S, Ogawa $T$ and Ito $\mathrm{H}$ : Immunohistochemical expression of geminin in colorectal cancer: implication of prognostic significance. Oncol Rep 21: 1189-1195, 2009.

18. Tokuyasu N, Shomori K, Nishihara K, et al: Minichromosome maintenance 2 (MCM2) immunoreactivity in stage III human gastric carcinoma: clinicopathological significance. Gastric Cancer 11: 37-46, 2008.

19. Nigg EA: Mitotic kinases as regulators of cell division and its checkpoints. Nat Rev Mol Cell Biol 2: 21-32, 2001.

20. Crosio C, Fimia GM, Loury R, et al: Mitotic phosphorylation of histone H3: spatio-temporal regulation by mammalian Aurora kinases. Mol Cell Biol 22: 874-885, 2002. 
21. Bischoff JR, Anderson L, Zhu Y, et al: A homologue of Drosophila aurora kinase is oncogenic and amplified in human colorectal cancers. EMBO J 17: 3052-3065, 1998.

22. Jeng YM, Peng SY, Lin CY and Hsu HC: Overexpression and amplification of Aurora-A in hepatocellular carcinoma. Clin Cancer Res 10: 2065-2071, 2004.

23. Kurahashi T, Miyake H, Hara I and Fujisawa M: Significance of Aurora-A expression in renal cell carcinoma. Urol Oncol 25 128-133, 2007.

24. Lam AK, Ong K and Ho YH: Aurora kinase expression in colorectal adenocarcinoma: correlations with clinicopathological features, p16 expression, and telomerase activity. Hum Pathol 39 599-604, 2008

25. Ogawa E, Takenaka K, Katakura H, et al: Perimembrane Aurora-A expression is a significant prognostic factor in correlation with proliferative activity in non-small cell lung cancer (NSCLC). Ann Surg Oncol 15: 547-554, 2008.

26. Shang X, Burlingame SM, Okcu MF, et al: Aurora A is a negative prognostic factor and a new therapeutic target in human neuroblastoma. Mol Cancer Ther 8: 2461-2469, 2009.

27. Tanaka E, Hashimoto Y, Ito T, et al: The clinical significance of Aurora-A/STK15/BTAK expression in human esophageal squamous cell carcinoma. Clin Cancer Res 11: 1827-1834, 2005.

28. Zhang XH, Rao M, Loprieato JA, et al: Aurora A, Aurora B and survivin are novel targets of transcriptional regulation by histone deacetylase inhibitors in non-small cell lung cancer. Cancer Biol Ther 7: 1390-1399, 2008

29. Williams GH and Stoeber K: Cell cycle markers in clinical oncology. Curr Opin Cell Biol 19: 672-679, 2007.

30. Sobin LH: UICC International Union Against Cancer: TNM classification of malignant tumours. 6th edition. John Wiley \& Sons, New York, 2002.

31. Suzuki K, Yokose T, Yoshida J, Nishimura M, Takahashi K, Nagai K and Nishiwaki Y: Prognostic significance of the size of central fibrosis in peripheral adenocarcinoma of the lung. Ann Thorac Surg 69: 893-897, 2000.
32. Stoeber K, Tlsty TD, Happerfield L, Thomas GA, Romanov S, Bobrow L, Williams ED and Williams GH: DNA replication licensing and human cell proliferation. J Cell Sci 114: 2027-2041, 2001.

33. Blow JJ and Hodgson B: Replication licensing - defining the proliferative state? Trends Cell Biol 12: 72-78, 2002.

34. Freeman A, Morris LS, Mills AD, Stoeber K, Laskey RA, Williams GH and Coleman N: Minichromosome maintenance proteins as biological markers of dysplasia and malignancy. Clin Cancer Res 5: 2121-2132, 1999.

35. Gonzalez MA, Tachibana KK, Laskey RA and Coleman N: Control of DNA replication and its potential clinical exploitation. Nat Rev Cancer 5: 135-141, 2005.

36. Montanari M, Macaluso M, Cittadini A and Giordano A: Role of geminin: from normal control of DNA replication to cancer formation and progression? Cell Death Differ 13: 1052-1056, 2006.

37. Gonzalez MA, Tachibana KE, Chin SF, et al: Geminin predicts adverse clinical outcome in breast cancer by reflecting cell-cycle progression. J Pathol 204: 121-130, 2004.

38. Marumoto T, Zhang DW and Saya H: Aurora-A: a guardian of poles. Nat Rev Cancer 5: 42-50, 2005.

39. Tong T, Zhong Y, Kong J, et al: Overexpression of Aurora-A contributes to malignant development of human esophageal squamous cell carcinoma. Clin Cancer Res 10: 7304-7310, 2004.

40. Royce ME, Xia WY, Sahin AA, et al: STK15/Aurora-A expression in primary breast tumors is correlated with nuclear grade but not with prognosis. Cancer 100: 12-19, 2004

41. Johnson KR, Wang L, Miller MC III, et al: 5-Fluorouracil interferes with paclitaxel cytotoxicity against human solid tumor cells. Clin Cancer Res 3: 1739-1745, 1997. 